\title{
Local changes in blood flow within the preovulatory follicle wall and early corpus luteum in cows
}

\author{
T. J. Acosta ${ }^{1 *}$, K. G. Hayashi ${ }^{2}$, M. Ohtani ${ }^{3}$ and A. Miyamoto ${ }^{2 \dagger}$ \\ ${ }^{1}$ Departamento de Fisiologia, Facultad de Ciencias Veterinarias Universidad Nacional de Asuncion, \\ Casilla de Correo 1061, San Lorenzo, Paraguay; ${ }^{2}$ Departments of Agricultural and Life Science; and \\ ${ }^{3}$ Field Centre of Animal Science and Agriculture, Obihiro University of Agriculture and Veterinary \\ Medicine, Obihiro 080-8555, Japan
}

Haemodynamic changes are involved in the cyclic remodelling of ovarian tissue that occurs during final follicular growth, ovulation and new corpus luteum development. The aim of this study was to characterize the realtime changes in the blood flow within the follicle wall associated with the LH surge, ovulation and corpus luteum development in cows. Normally cyclic cows with a spontaneous ovulation $(n=5)$ or a $\mathrm{GnRH}$-induced ovulation $(n=5)$ were examined by transrectal colour and pulsed Doppler ultrasonography to determine the area and the time-averaged maximum velocity (TAMXV) of the blood flow within the preovulatory follicle wall and the early corpus luteum. Ultrasonographic examinations began $48 \mathrm{~h}$ after a luteolytic injection of $\mathbf{P G F}_{2 \alpha}$ analogue was given at the mid-luteal phase of the oestrous cycle. Cows with spontaneous ovulation were scanned at $6 \mathrm{~h}$ intervals until ovulation occurred. Cows with GnRH-induced ovulation were scanned just before $\mathrm{GnRH}$ injection $(0 \mathrm{~h})$, thereafter at $0.5,1,2,6,12,24 \mathrm{~h}$ and at $24 \mathrm{~h}$ intervals up to day 5. Blood samples were collected at the same time points for oestradiol, LH and progesterone determinations. Cows with both spontaneous and $\mathrm{GnRH}$-induced ovulation showed a clear increase in the plasma concentration of LH (LH surge) followed by ovulation 26-34 h later. In the colour Doppler image of the preovulatory follicle, the blood flow before the LH surge was detectable only in a small area in the base of the follicle. An acute increase in the blood flow velocity (TAMXV) was detected at $0.5 \mathrm{~h}$ after GnRH injection, synchronously with the initiation of the LH surge. At $12 \mathrm{~h}$ after the LH surge, the plasma concentrations of oestradiol decreased to basal concentrations. The TAMXV remained unchanged after the initial increase until ovulation, but decreased on day 2 (12-24 $h$ after ovulation). In the early corpus luteum, the blood flow (area and TAMXV) gradually increased in parallel with the increase in corpus luteum volume and plasma progesterone concentration from day 2 to day 5 , indicating active angiogenesis and normal luteal development. Collectively, the complex structural, secretory and functional changes that take place in the ovary before ovulation are closely associated with a local increase in the blood flow within the preovulatory follicle wall. The result of the present study provides the first visual information on vascular and blood flow changes associated with ovulation and early corpus luteum development in cows. This information may be essential for future studies involving pharmacological control of blood flow and alteration of ovarian function.

\section{Introduction}

Haemodynamic changes are involved in the cyclic remodelling of ovarian tissue that occurs during final follicular growth, ovulation and new corpus luteum development (Moor et al., 1975; Collins et al., 1991; Brannstrom et al., 1998; Acosta et al., 2002). Extensive vascular formation (angiogenesis) and cell differentiation (luteinization) occur in the follicular wall during the period between the LH surge and early corpus luteum

*Present address: Department of Animal Health and Biomedical Sciences, University of Wisconsin, Madison, WI 53706, USA ${ }^{\dagger}$ Correspondence

E-mail: akiomiya@obihiro.ac.jp development. At ovulation, follicles collapse and release the ovum and antral fluid. When the basement membrane is destroyed, new vessels develop from pre-existing thecal vasculature. The intensity of this angiogenic process reaches a peak $2-3$ days later in the early corpus luteum (Reynolds et al., 2000).

Colour Doppler ultrasonography is a useful, noninvasive technique for evaluating ovarian vascular function, allowing a visual observation of the blood flow in a delimited area in the wall of preovulatory follicles (Brannstrom et al., 1998) or within the corpus luteum (Miyazaki et al., 1998; Acosta et al., 2002). This imaging has facilitated haemodynamic studies and reproducible measurements (Collins et al., 1991; Brannstrom et al., 1998; Acosta et al., 2002). A recent 
ultrasonographic study designed to investigate regional changes of blood flow in the human follicle demonstrated that blood flow is evenly distributed in the dominant follicle during the late follicular phase and before the $\mathrm{LH}$ surge. However, after the LH surge, there are prominent changes in the regional blood flow of the follicle with a marked increase of the flow to the base of the follicle and a concomitant decrease of blood flow to the apex (Brannstrom et al., 1998). Thus, blood flow determinations of individual preovulatory follicles prior to follicular aspiration for IVF therapy provide an important index on the intrafollicular environment and may predict the developmental competence of the corresponding oocyte (Coulam et al., 1999; Huey et al., 1999).

$\mathrm{LH}$ induces an increase in ovarian blood flow in rats (Varga et al., 1985), rabbits (Janson, 1975) and sheep (Niswender et al., 1976). However, the mechanisms of $\mathrm{LH}$-induced hyperaemia remain unknown. Since LH has no direct vascular effect (Varga et al., 1985), a mediatory role of vasoactive substances released during LH stimulation in the bovine preovulatory follicle was postulated by Acosta et al. (1999). Vasoactive substances play important roles in ovulation as well as in early luteal development, by modulating the local secretion of prostaglandin and steroid hormones (Acosta et al., 1999, 2000; Kobayashi et al., 2002). One of the main points for understanding the roles of vasoactive substances in ovarian physiology is to determine the changing profile of local blood flow in individual follicles and corpus luteum at specific stages of the oestrous cycle. However, there is no information available on the local changes in blood flow during the period of active vascular remodelling that occurs around the time of ovulation in cows. Therefore, the aim of the present study was to characterize the realtime changes in the blood flow within the follicle wall at the last stage of follicular maturation associated with the LH surge, ovulation and new corpus luteum development in cows.

\section{Materials and Methods}

\section{Animals and ultrasonography}

The animal experiment was carried out at the Field Centre of Animal Science and Agriculture, Obihiro University. Experimental procedures complied with the Guide for Care and Use of Agriculture Animals of Obihiro University. Lactating Holstein cows were kept under normal management programme of the Field Centre and fed daily with corn silage, hay and concentrate with permanent free access to water. At the middle stage of the oestrous cycle cows received $500 \mu \mathrm{g}$ of a $\mathrm{PGF}_{2 \alpha}$ analogue (cloprostenol (Estrumate); Sumitomo Pharm. Co., Osaka) i.m. to induce luteolysis, and $48 \mathrm{~h}$ later cows were randomly separated into two groups. The first group of cows was allowed to ovulate spontaneously
( $n=5$ ) and was then examined at $6 \mathrm{~h}$ intervals until ovulation was confirmed. In the second group $(n=5)$, ovulation was induced by a $\mathrm{GnRH}$ analogue (Fertirelin acetate $100 \mu g$; (Conceral); Nagase Pharm. Co., Osaka, Japan) injected $48 \mathrm{~h}$ after $\mathrm{PGF}_{2 \alpha}$. Possible acute changes in the blood flow during the increase in the plasma concentration of LH that was induced by the $\mathrm{GnRH}$ analogue injection were determined by scanning the $\mathrm{GnRH}$-induced ovulation group just before GnRH injection $(0 \mathrm{~h})$ and then at $0.5,1,2,6,12,24$, 48, 72, 96 and $120 \mathrm{~h}$. Blood samples were collected for oestradiol, $\mathrm{LH}$ and progesterone determinations. Blood samples were collected at $2 \mathrm{~h}$ intervals from cows with spontaneous ovulation and just before each ultrasonographic examination for the $\mathrm{GnRH}$-induced ovulation group.

The follicles and corpus luteum were examined by transrectal ultrasonography using an ultrasound scanner (Aloka SSD-1700, Mitaka, Tokyo) equipped with a 7.5 MHz convex transducer (UST-995-7.5) in a standardized procedure as described by Acosta et al. (2002). All scans were performed by the same investigator (T. J. Acosta). During each ultrasonographic examination, the volume $(V)$ of the follicles and corpus luteum were estimated using the following equation for a modified prolate ellipsoid: $V=0.523 \times A \times B \times B$, in which $A$ represents the maximum length and $B$ represents the transverse diameter. After morphological evaluation, the flow mode was activated for blood flow mapping. Colour signals were used to generate images in which blood flow was detectable within the follicle wall and developing corpus luteum. These images were used to evaluate the blood flow in a vertical plane from the apex to the base of the follicle or corpus luteum, the sectional area $(S A)$ of the follicle and corpus luteum $S A=\pi / 4 \times(S D)^{2}$, where $S D$ is the sectional diameter. The coloured area in the image obtained in a vertical plane at the maximum diameter of both structures from the apex to the base was used as a quantitative index to express the blood flow within the follicle wall and early corpus luteum. The degree of turbulence is indicated as colour-coded signal. The brightness of the colour is proportional to the velocity of flow within the vessel. Areas of colour represent regions with a flow velocity higher than $2 \mathrm{~cm} \mathrm{~s}^{-1}$.

Blood flow velocity wave forms were recorded during three cardiac cycles to determine the time-averaged maximum velocity (TAMXV) in the base of the follicle and corpus luteum by placing the sample volume across the vessel that displayed the most intensive colour signal and switching on the pulsed Doppler mode. The pulsed Doppler sample volume was set at $1 \mathrm{~mm}$ width. All scans were performed at a pulse repetition frequency of $6 \mathrm{~Hz}$. Identical colour gain settings were used for all scanning. During each scanning, the distance between the transducer face and corpus luteum was minimized $(1-2 \mathrm{~cm})$ to reduce signal attenuation. The angle of insonation was not calculated because of the small 
(a)

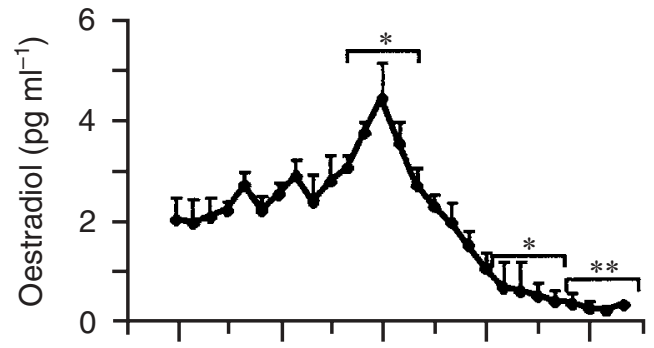

(c)

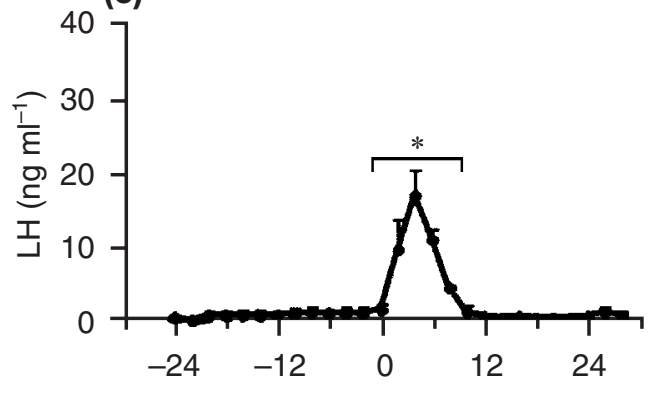

(b)

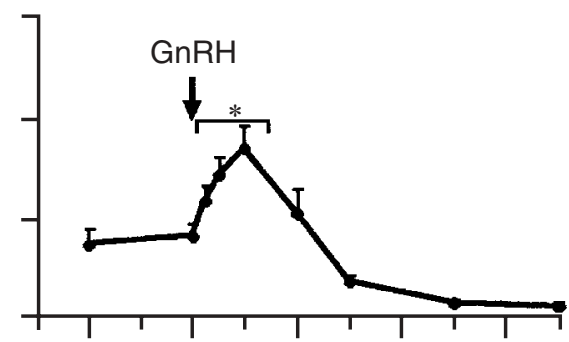

(d)

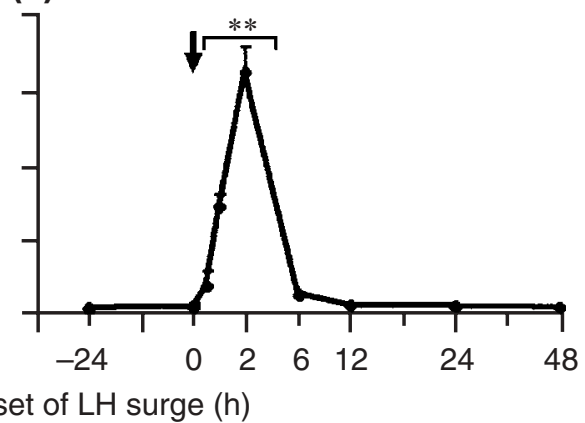

Fig. 1. Changes in the plasma concentration of $(a, b)$ oestradiol and $(c, d) L H$ relative to the onset of $\mathrm{LH}$ surge $(0 \mathrm{~h})$ for $(\mathrm{a}, \mathrm{c})$ spontaneous ovulation and $(\mathrm{b}, \mathrm{d}) \mathrm{GnRH}$-induced ovulation. Data points show mean \pm SEM of each time period ( $n=5$ cows per group). ${ }^{*} P<0.05,{ }^{* *} P<0.01$ versus values before the onset of LH surge.

diameter of vessels investigated, but care was taken to obtain the maximum colour intensity. Scan records (images) were stored on a magneto-optical $(\mathrm{MO})$ disk drive for a personal computer (Macintosh; Apple Corp., San Jose, CA) and then viewed on the monitor. The coloured area was selected and changed to a black and white image using Adobe Photoshop 5.5 program. The same image was used to calculate the sectional area, and the coloured area was quantified using the $\mathrm{NIH}$ Image program (Version 1.62) developed at the US National Institutes of Health (http://rsb.info.nih.gov/nihimage). The sum of the areas in which blood flow was detected were calculated from at least five different cows per group at each time point and expressed as mean \pm SEM.

\section{Progesterone, oestradiol and $L H$ determinations}

Blood samples were obtained by caudal venepuncture just before each scanning using sterile $10 \mathrm{ml}$ tubes containing $200 \mu \mathrm{l}$ of a stabilizer solution (0.3 mol EDTA $\mathrm{I}^{-1}, 1 \%(\mathrm{w} / \mathrm{v})$ acetyl salicylic acid, $\left.\mathrm{pH} 7.4\right)$. All tubes were immediately chilled in ice-water for $10 \mathrm{~min}$, centrifuged at $2000 \mathrm{~g}$ for $10 \mathrm{~min}$ at $4{ }^{\circ} \mathrm{C}$, and the obtained plasma was stored at $-30^{\circ} \mathrm{C}$ until the analysis of the plasma concentrations of progesterone, oestradiol and $\mathrm{LH}$. At the end of the experiment, all samples from each cow were analysed in the same assay in duplicate using second antibody enzymeimmunoassays. Steroid assays were performed after diethyl ether extraction: for oestradiol determination, plasma was concentrated tenfold, allowing the measurement of oestradiol concentrations by enzymeimmunoassays within the optimal range of the standard curve as described by Acosta et al. (2000). The standard curve for progesterone ranged from 0.05 to $25 \mathrm{ng} \mathrm{ml}^{-1}$. The intra- and interassay coefficients of variations (CVs) were 4.7 and $6.5 \%$, respectively. The recovery rate of progesterone $(5 \mathrm{ng})$ added to $1 \mathrm{ml}$ plasma samples was 92\% $(n=10)$. Likewise $15 \mu \mathrm{l}$ of samples were analysed for oestradiol. The standard curve ranged from 2 to $2000 \mathrm{pg} \mathrm{ml}^{-1}$. The intra- and interassay CVs were 6.8 and $8.6 \%$, respectively. The recovery rate of oestradiol (10 pg) added to $5 \mathrm{ml}$ plasma samples was $73 \%(n=10)$. The LH concentration was determined directly in duplicate $15 \mu \mathrm{l}$ plasma samples using a sensitive enzymeimmunoassay for LH determination in bovine plasma based on the streptavidin-biotin technique as described by Mutayoba et al. (1990). The standard curve for LH ranged from 0.4 to $200 \mathrm{ng} \mathrm{ml}^{-1}$. The intra- and interassay CVs were 8.7 and $13.3 \%$, respectively.

\section{Statistical analysis}

The onset of the LH surge in the spontaneous ovulation group or the $\mathrm{GnRH}$ analogue injection $(\mathrm{GnRH}$ induced ovulation group) was defined as $0 \mathrm{~h}$. Plasma 


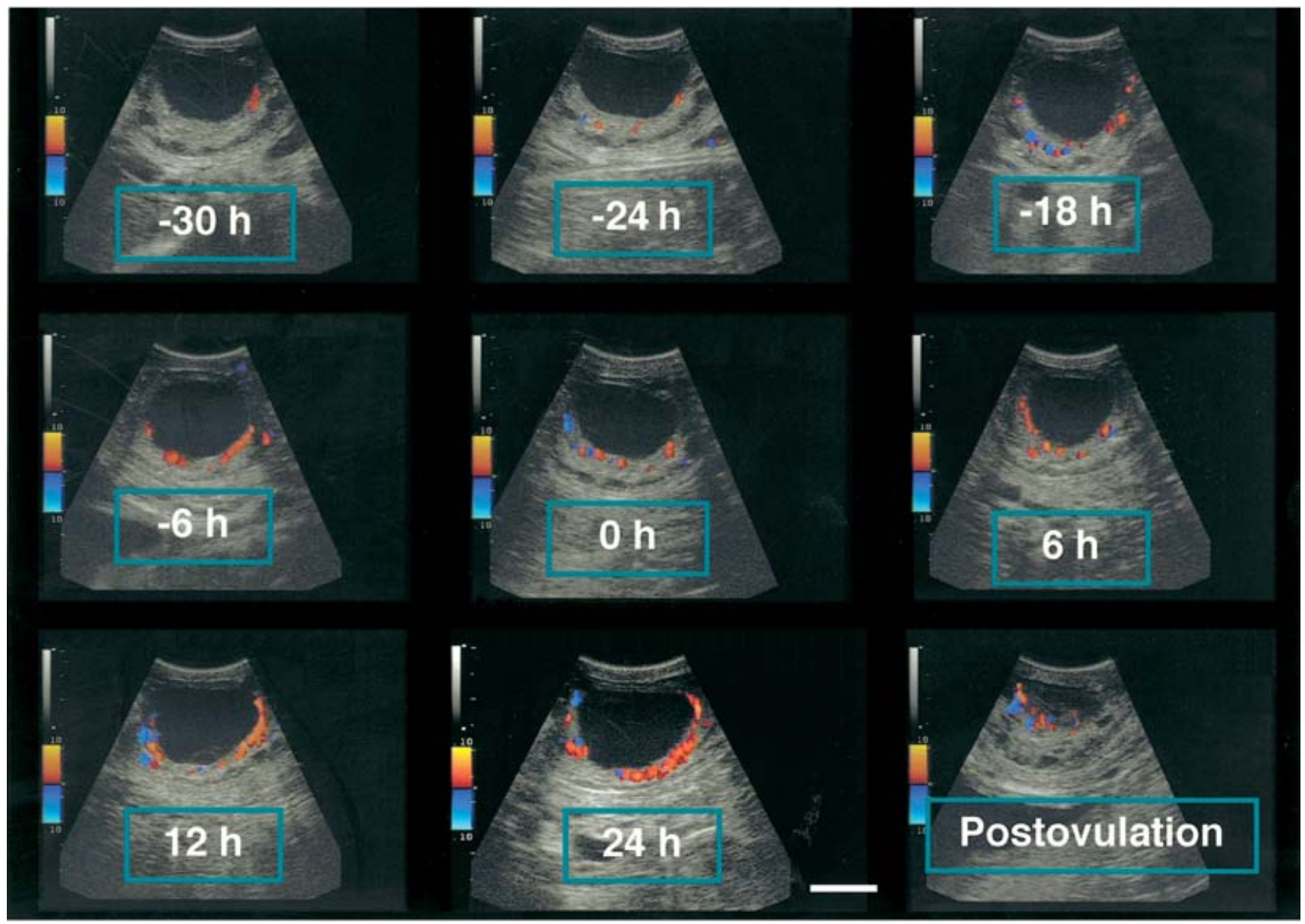

Fig. 2. Representative images of the time-related changes in preovulatory follicle of cows with spontaneous ovulation showing a gradual increase in the blood flow area as ovulation approaches. Red colour indicates blood flow toward the transducer, and blue indicates blood flow away from the transducer. The colour gain of the flow mode was set to detect movement of at least $2 \mathrm{~cm} \mathrm{~s}^{-1}$. Scale bar represents $1 \mathrm{~cm}$.

concentrations of oestradiol, progesterone, $\mathrm{LH}$ and TAMXV are presented as mean \pm SEM. The coloured area with a detectable blood flow within the follicle wall and early corpus luteum was expressed also as mean \pm SEM. Data were examined by repeated measures ANOVA with time as the variable tested. Where significant effects of time were found $(P<0.05)$, the test of leastsignificant difference was used to identify which points were different from those values obtained before LH surge or $\mathrm{GnRH}$ injection.

\section{Results}

Cows with spontaneous and GnRH-induced ovulation showed similar time-dependent endocrine and structural profiles. The changing profiles of plasma oestradiol and LH surge were comparable between the two groups (Fig. 1), and cows in both groups ovulated 24-36 h after LH surge (Figs 2 and 3 ) and showed normal corpus luteum development (Fig. 4c and d). Images of an anovulatory follicle and a preovulatory follicle are shown (Fig. 4a). The atretic follicle was characterized by a lack of detectable blood flow and a progressive decrease in diameter. The preovulatory follicle was well vascularized with a detectable blood flow surrounding the antrum in the base of the follicle. The well vascularized follicle ovulated (Fig. 4b) and an early corpus luteum developed (Fig. 4c,d). However, the atretic follicle remained in contact with the developing corpus luteum up to day 5 , but the antrum cavity was not detected on day 8 of the next cycle.

\section{Changes in the plasma concentrations of oestradiol and $\mathrm{LH}$}

In cows with spontaneous ovulation, plasma concentration of oestradiol gradually increased from $2.1 \pm$ $0.4 \mathrm{pg} \mathrm{ml}^{-1}$ at $-24 \mathrm{~h}$ to $4.7 \pm 0.7 \mathrm{pg} \mathrm{m}^{-1}$ at the time of the onset of the $\mathrm{LH}$ surge $(0 \mathrm{~h})$. In the $\mathrm{GnRH}$ induced ovulation group, plasma oestradiol and $\mathrm{LH}$ concentrations acutely increased after $\mathrm{GnRH}$ injection 


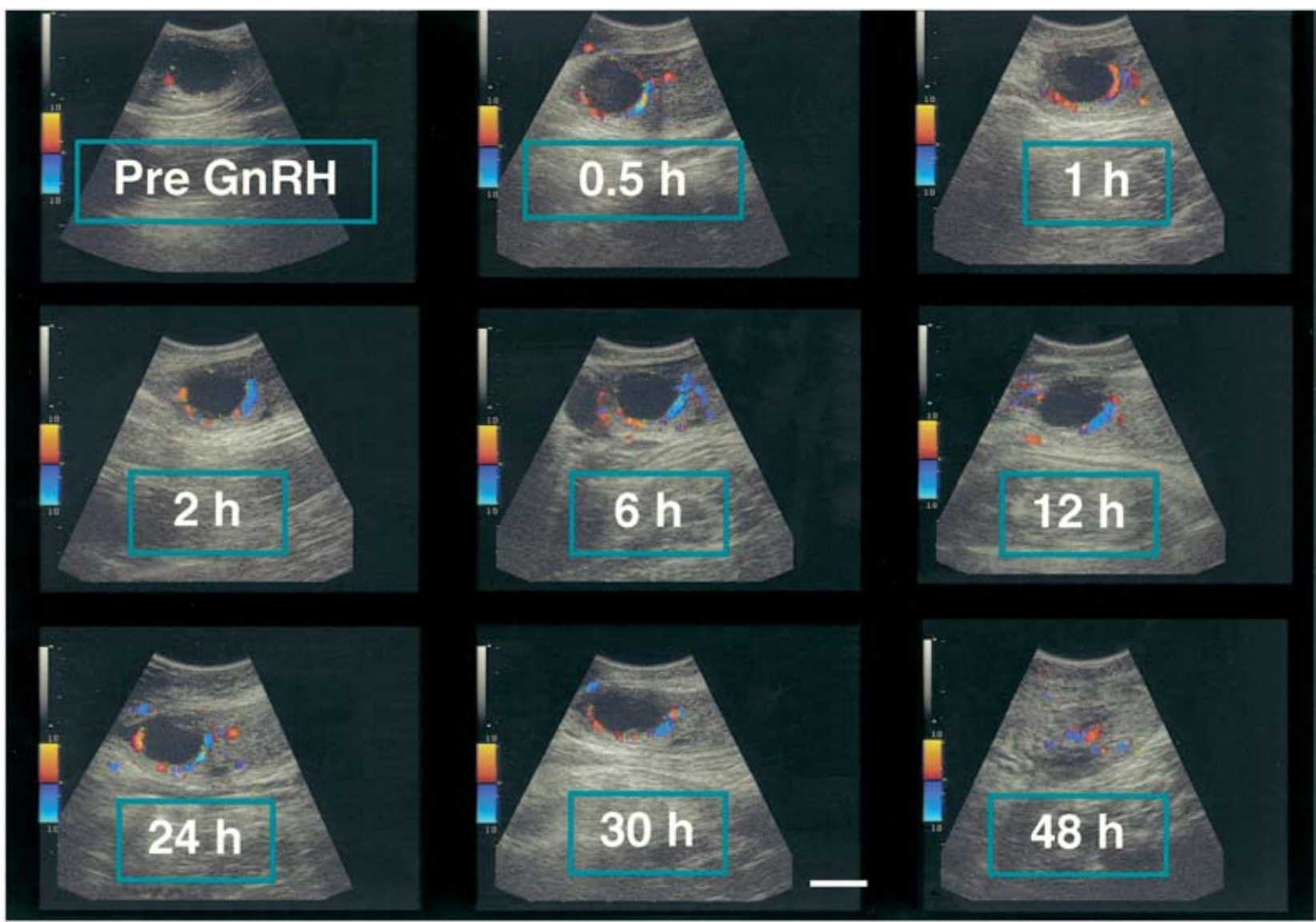

Fig. 3. Representative images of preovulatory follicles of cows with $\mathrm{GnRH}$-induced ovulation showing acute increases in the blood flow area and the intensity of colour (velocity) after injection of a GnRH analogue. Red represents the blood flow toward the transducer, and blue indicates blood flow away from the transducer. The colour gain of the flow mode was set to detect movement of at least $2 \mathrm{~cm} \mathrm{~s}^{-1}$. Scale bar represents $1 \mathrm{~cm}$.

and reached a peak $2 \mathrm{~h}$ later. After the $\mathrm{LH}$ surge, oestradiol concentration decreased $(P<0.05)$ at $12 \mathrm{~h}$ and remained at basal concentrations after $24 \mathrm{~h}$ in both groups (Fig. 1). The peak of plasma LH concentrations in GnRH-induced ovulation group was higher than that of cows with spontaneous ovulation $\left(32 \pm 7 \mathrm{ng} \mathrm{ml}^{-1}\right.$ versus $\left.15 \pm 5 \mathrm{ng} \mathrm{ml}^{-1}, P<0.05\right)$ but the duration of the $\mathrm{LH}$ surge was shorter: $6 \mathrm{~h}$ versus $12 \mathrm{~h}$, respectively.

\section{Changes in the blood flow area and TAMXV within the} follicle wall

Colour Doppler images of the preovulatory follicle of cows with spontaneous ovulation and $\mathrm{GnRH}$-induced ovulation are shown (Figs 2 and 3, respectively). The area with detectable blood flow was limited to the base of the follicle at $48 \mathrm{~h}$ after PG injection, when plasma LH concentration remained basal. This area was $0.06 \pm 0.02 \mathrm{~cm}^{2}$ in both groups. In cows with spontaneous ovulation, the flow area gradually increased in parallel with plasma oestradiol concentration and remained high until ovulation. However, after GnRH injection the flow area expanded in the follicle wall occupying $0.15 \pm 0.03 \mathrm{~cm}^{2}$ at $30 \mathrm{~min}$. These values remained higher $(P<0.05)$ than those values observed before spontaneous or $\mathrm{GnRH}$-induced $\mathrm{LH}$ surge (Fig. 5).

In the preovulatory follicle wall, the highest TAMXV values were detected during increasing plasma LH concentrations in both groups. However, in cows with $\mathrm{GnRH}$-induced ovulation, the TAMXV increased synchronously with the flow area and remained relatively unchanged until ovulation (Fig. 5). In spontaneously ovulating cows, follicular blood flow area started to increase when plasma $\mathrm{LH}$ concentration still remained low (Fig. 5).

Changes in plasma progesterone concentration, corpus luteum volume, TAMXV and flow area during early corpus luteum development

In the early corpus luteum, the blood flow area gradually increased in parallel with the increase in corpus luteum volume, plasma progesterone concentration, and 


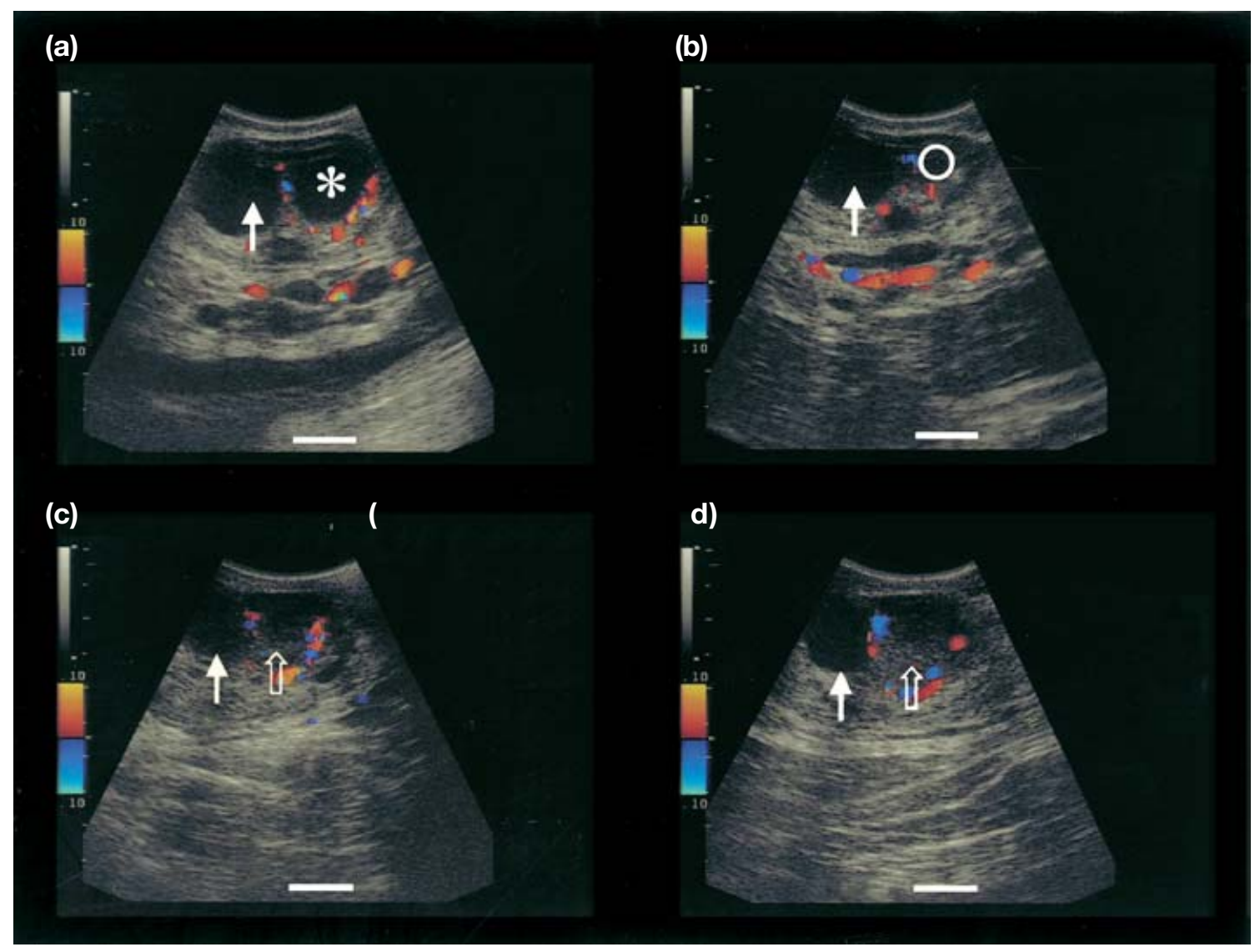

Fig. 4. Images of a preovulatory follicle $\left(^{*}\right)$ and an atretic follicle (close arrow) of similar size showing clear differences in the vascularization and blood flow area in the follicular wall (a) $24 \mathrm{~h}$ after a GnRH analogue injection, (b) just after ovulation (open circle), and (c,d) during early corpus luteum development (open arrows). The atretic follicle was still visible on day 4 of the next cycle, but the antrum cavity was not detected on day 8 . The colour gain was set to detect movement of at least $2 \mathrm{~cm} \mathrm{~s}^{-1}$. Scale bars represent $1 \mathrm{~cm}$.

TAMXV from $48 \mathrm{~h}$ to $120 \mathrm{~h}$ (Fig. 6). The highest value of TAMXV was observed at $120 \mathrm{~h}$. Between $72 \mathrm{~h}$ and $96 \mathrm{~h}$, the blood flow area and the volume of early corpus luteum increased two- to threefold, indicating active angiogenesis and normal corpus luteum development.

\section{Discussion}

The results of the present study provide the first visual evidence for the time-related changes in the blood flow within the preovulatory follicle wall of cows with spontaneous and $\mathrm{GnRH}$-induced ovulation. The image of the preovulatory follicles revealed that blood flow area and TAMXV were temporally associated with the increase in plasma concentration of oestradiol and the $\mathrm{LH}$ surge. The results indicate that there is a functional relationship between blood flow in the follicular wall and plasma concentration of oestradiol and $\mathrm{LH}$ during the periovulatory period in the cow.

The first detectable increase in plasma oestradiol concentration was coincident with an increase in the vascularization (blood flow area) in the follicle wall.
The result agrees with previous studies in which the follicular diameter, oestradiol concentration in follicular fluid and the vascular area were closely associated with each other (Mattioli et al., 2001). Oestrogen has been postulated as an essential factor in the regulation of blood flow of the reproductive tract (Moor et al., 1975). After GnRH injection, both follicular blood flow and plasma concentrations of LH and oestradiol increased simultaneously. This phenomenon may induce an acute change in the metabolic function of follicular cells, resulting in increasing production of steroids and vasoactive substances. Oestrogen may cause a rapid dilation of blood vessels by activating endothelial nitric oxide synthase (eNOS). In studies of intact artery endothelial cells of lambs, oestradiol treatment resulted in acute $(5 \mathrm{~min})$ activation of eNOS that was fully inhibited by concomitant treatment with oestrogen receptor (ER) $\alpha$ antagonists, suggesting that the shortterm effects of oestrogen are mediated by $E R \alpha$ (Chen et al., 1998). This local vasodilatory substance acts directly in the regulation of the blood flow in the ovary. The increase in the blood flow in the preovulatory 
(a)

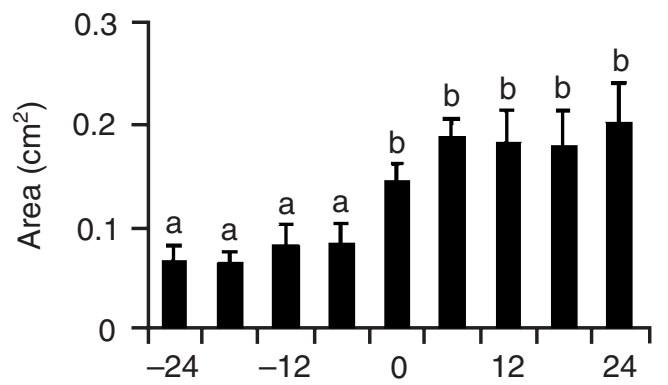

(c)

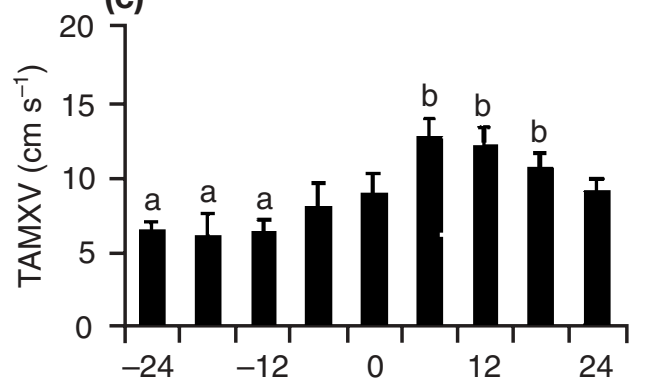

(b)

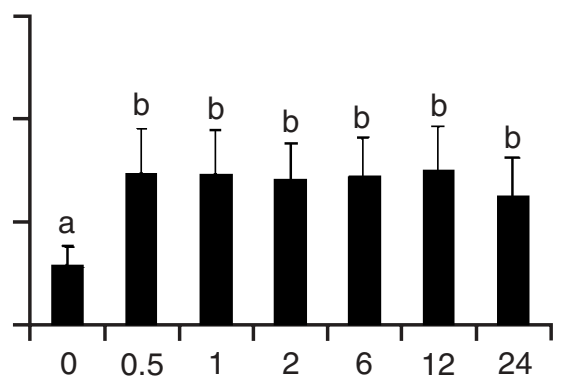

(d)

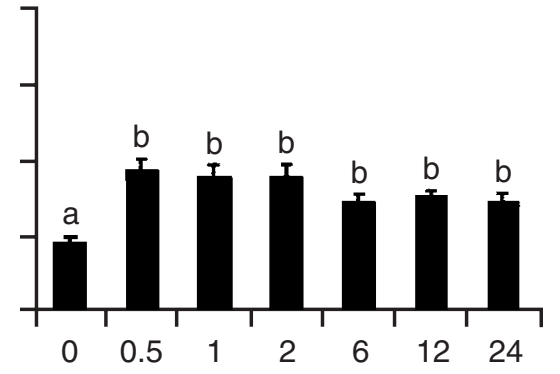

Time relative to the onset of LH surge (h)

Fig. 5. Changes in $(a, b)$ the area of detectable blood flow in the follicle wall and (c,d) Doppler-derived timeaveraged maximum velocity (TAMXV) of cows with $(a, c)$ spontaneous ovulation and (b,d) GnRH-induced ovulation. The TAMXV was measured in the base of the follicle with colour Doppler ultrasonography. Data points show mean \pm SEM for each time period ( $n=5$ cows per group). ${ }^{a, b}$ Values with different letters are significantly different $(P<0.05)$.

(a)

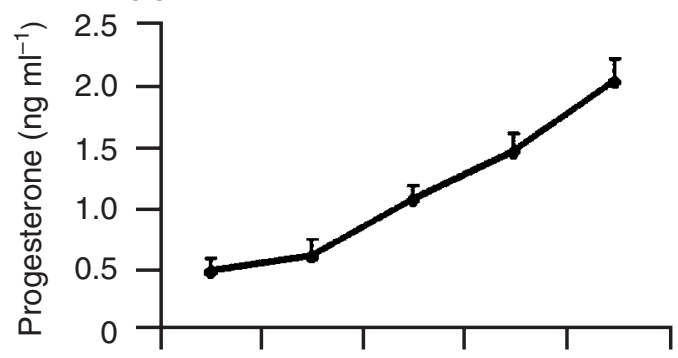

(c)

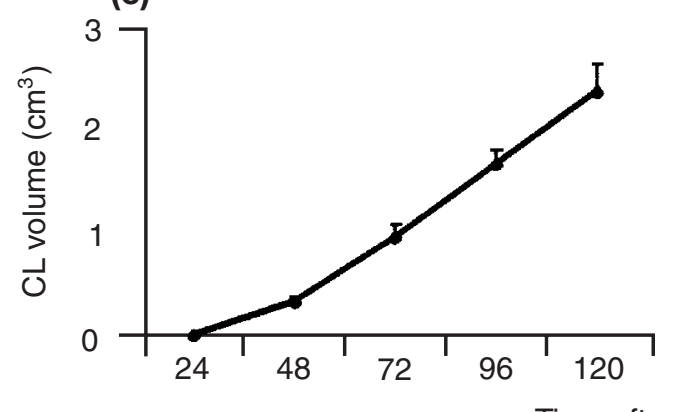

(b)

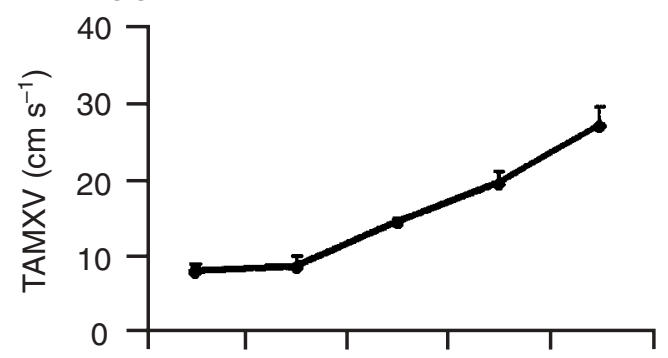

(d)

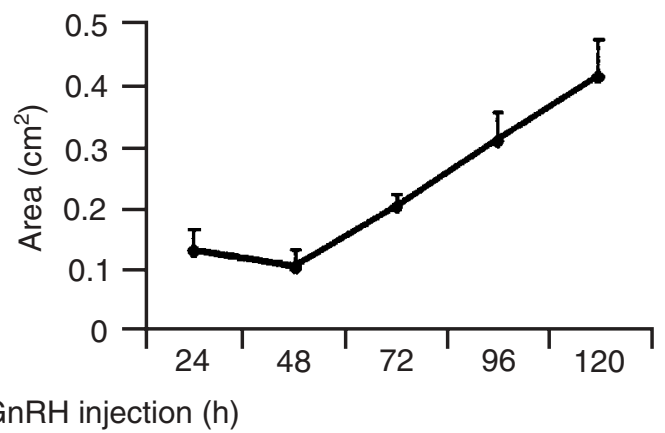

Fig. 6. Changes in (a) the plasma concentrations of progesterone, (b) time-averaged maximum velocity (TAMXV), (c) corpus luteum volume and (d) blood flow area during early corpus luteum development $(24 \mathrm{~h}$ to $120 \mathrm{~h}$ ) after $\mathrm{GnRH}$ injection $(0 \mathrm{~h})$. Data points show mean $\pm \mathrm{SEM}$ of each time period ( $n=5$ cows). 
follicle wall may increase the supply to follicular cells of gonadotrophins, nutrients, hormonal substrates and other blood components necessary for ovulation.

LH induced an increase in follicular blood flow in rats (Varga et al., 1985), rabbits (Janson, 1975), and sheep (Niswender et al., 1976). It has been demonstrated that LH does not alter blood pressure but decreases vascular resistance in the rat ovary (Varga et al., 1985). Since $\mathrm{LH}$ has no direct vascular effect, a mediatory role of vasoactive substances released during $\mathrm{LH}$ stimulation has been postulated (Acosta et al., 1999). After the LH surge, the blood flow in the apex decreases while it increases at the base of the human follicle (Brannstrom et al., 1998). Paracrine and autocrine factors produced in the ovary are also critical for follicular rupture (Giudice et al., 1993; Pepperell et al., 1995; Yoshimura, 1997). Several studies have demonstrated that vasoactive substances derived from endothelium, fibroblasts, leukocytes and follicular cells interact with each other and modify the actions of gonadotrophins at the ovaries (Brannstrom et al., 1993; Tedeschi et al., 1994). An in vitro study using isolated bovine mature follicles demonstrated that an LH infusion increased endothelin 1 release from the theca layer (Acosta et al., 1998). The following study demonstrated that angiotensin II, endothelin 1 and atrial natriutretic peptide increased follicular PGs secretion and modified steroidogenesis (Acosta et al., 1999). The above findings indicate there may be cross-talk between vascular components (endothelial cells) and follicular steroidogenic cells that may modulate the local changes in the blood flow observed in the ovulatory follicle in the present study.

The $\mathrm{LH}$ surge induces prominent structural changes in the ovarian extracellular matrix as well as a redistribution of the blood flow in the follicular wall several hours before ovulation (Espey, 1994). The degradation of the collagen layers in the follicular wall are accompanied by increased vascular dilatation and permeability (Murdoch et al., 1986). In the present study, a clear difference was observed in the images of a preovulatory follicle in which the blood flow area was evident surrounding the antral cavity and an atretic (anovulatory) follicle that lacked detectable blood flow and decreased progressively in diameter. Positive correlation among follicular blood velocity, oocyte recovery and the production of a highgrade preimplantation embryo was found in humans (Nargund et al., 1996; Coulam et al., 1999). The above data demonstrate that follicular vascularization and blood flow velocity could be used to identify healthy follicles as well as to predict the proximity of ovulation.

At ovulation, the follicle collapses and releases the ovum and antral fluid. There is a loss of the basement membrane and new vessels develop from pre-existing thecal vasculature. This period of intensive angiogenesis continues within the developing early corpus luteum. As a result of this process, the corpus luteum becomes one of the most highly vascularized organs and receives the greatest rate of blood flow per unit of tissue for any organ in the body (Wiltbank et al., 1988). In the present study, the marked increase in the blood flow and the volume of the early corpus luteum were closely associated with the potential to produce and release progesterone, reflected in the parallel increase in the plasma concentration of progesterone that indicates normal corpus luteum development. It is also of interest to note that marked differences in the vascular area and TAMXV of follicles between the period of pre- and post$\mathrm{LH}$ surge confirm the hypothesis that oestradiol and $\mathrm{LH}$ act together in increasing the blood flow to the dominant follicle. However, whether this is a direct or mediated effect remains to be determined.

In conclusion, the data confirm the concept that the complex structural and functional changes induced by the $\mathrm{LH}$ surge in a mature follicle are closely associated with a local increase in the blood flow within the preovulatory follicle wall. This information will be valuable for future studies involving pharmacological control of blood flow to alter ovarian function.

The authors thank K. Okuda (Okayama University, Japan) for progesterone antiserum. This study was supported by the Grant-inAid for Scientific Research of the Japan Society for the Promotion of Science (JSPS), the 21st Century COE Program (A-1) of Ministry of Education, Culture, Sports, Science, and Technology, Japan, and the Inoue Foundation for Science (IFS). T. J. Acosta was a postdoctoral fellow supported by JSPS and IFS.

\section{References}

Acosta TJ, Miyamoto A, Ozawa T, Wijayagunawuardane MPB and Sato K (1998) Local release of steroid hormones, prostaglandin E2, and endothelin-1 from bovine mature follicles in vitro: effects of luteinizing hormone, endothelin-1 and cytokines Biology of Reproduction 59 437443

Acosta TJ, Berisha B, Ozawa T, Sato K, Schams D and Miyamoto A (1999) Evidence for a local endothelin-angiotensin-atrial natriuretic peptide system in bovine mature follicles in vitro: effects on steroid hormones and prostaglandin secretion Biology of Reproduction 61 1419-1425

Acosta TJ, Ozawa T, Kobayashi S, Hayashi K, Ohtani M, Kraetzel WD, Sato K, Schams D and Miyamoto A (2000) Periovulatory changes in the local release of vasoactive peptides, prostaglandin $F_{2 \alpha}$ and steroid hormones from bovine mature follicles in vivo. Biology of Reproduction 63 1253-1261

Acosta TJ, Yoshizawa N, Ohtani M and Miyamoto A (2002) Local changes in blood flow within the early and midcycle corpus luteum after prostaglandin $\mathrm{F}_{2 \alpha}$ injection in the cow Biology of Reproduction 66651 658

Brannstrom M, Wang L and Norman RJ (1993) Effects of cytokines on prostaglandin production and steroidogenesis of incubated follicles of the rat Biology of Reproduction 48 165-171

Brannstrom $M$, Zackrisson $U$, Hagstrom $H$, Josefsson B, Hellberg $P$, Granberg S, Collins W and Bourne T (1998) Preovulatory changes of blood flow in different regions of the human follicle Fertility and Sterility 69 435-442

Chen Z, Yuhanna IS, Galcheva-Gargova Z, Karas RH, Mendelsohn ME and Shaul PW (1998) Estrogen receptor alpha mediates the nongenomic activation of endothelial nitric oxide synthase by estrogen Clinical Investigation 103 401-406 
Collins W, Jurkovic D, Bourne T, Kurjak A and Campbell S (1991) Ovarian morphology, endocrine function and intra-follicular blood flow during the peri-ovulatory period Human Reproduction 6 319-324

Coulam CB, Goodman C, and Rinehart JS (1999) Colour doppler indices of follicular blood flow as predictors of pregnancy after in-vitro fertilization and embryo transfer Human Reproduction 14 1979-1982

Espey LL (1994) Current status of the hypothesis that mammalian ovulation is comparable to an inflammatory reaction Biology of Reproduction $\mathbf{5 0}$ 233-238

Giudice LC, Chandrasekher YA and Cataldo NA (1993) The potential roles of intraovarian peptides in normal and abnormal mechanisms of reproductive physiology Current Opinion in Obstetrics and Gynecology 5 350-359

Huey S, Abuhamad A, Barroso G, Hsu MI, Kolm P, Mayer J and Oehninger S (1999) Perifollicular blood flow Doppler indices, but not follicular $\mathrm{pO}_{2}, \mathrm{pCO}_{2}$, or $\mathrm{pH}$, predict oocyte developmental competence in in vitro fertilization Fertility and Sterility 72 707-712

Janson PO (1975) Effects of luteinizing hormone on blood flow in the follicular rabbit ovary, as measured by radioactive microspheres Acta Endocrinology 79 122-133

Kobayashi S, Acosta TJ, Ozawa T, Hayashi K, Berisha B, Ohtani M, Schams D and Miyamoto A (2002) Intraluteal release of angiotensin II and progesterone in vivo during corpora lutea development in the cow: effect of vasoactive peptides Biology of Reproduction 66 174-179

Mattioli M, Barboni B, Turriani M, Galeati G, Zannoni A, Castellani G, Berardinelli P and Scapolo PA (2001) Follicle activation involves vascular endothelial growth factor production and increased blood vessel extension Biology of Reproduction 65 1014-1019

Miyazaki T, Tanaka M, Miyakoshi K, Minegishi K, Kasai K, Yoshimura Y (1998) Power and colour Doppler ultrasonography for the evaluation of the vasculature of the human corpus luteum Human Reproduction $\mathbf{1 3}$ 2836-2841

Moor RM, Hay MF and Seamark RF (1975) The sheep ovary: regulation of steroidogenic, haemodynamic and structural changes in the largest follicle and adjacent tissue before ovulation Journal of Reproduction and Fertility 45 595-604

Murdoch WJ, Peterson TA, Van Kirk EA, Vincent DL and Inskeep EK (1986) Interactive roles of progesterone, prostaglandins, and collagenase in the ovulatory mechanism of the ewe Biology of Reproduction 35 1187-1194

Mutayoba B, Meyer H, Schams D and Schallenberger E (1990) Development of a sensitive enzymeimmunoassay for LH determination in bovine plasma using the streptavidin-biotin technique Acta Endocrinology (Copenhagen) 122 227-232

Nargund G, Bourne T, Doyle P, Parsons J, Cheng W, Campbell S and Collins W (1996) Associations between ultrasound indices of follicular blood flow, oocyte recovery and preimplantation embryo quality Human Reproduction 11 109-113

Niswender GD, Reimers TJ, Diekman MA and Nett TM (1976) Blood flow: a mediator of ovarian function Biology of Reproduction 14 64-81

Pepperell JR, Yamada Y, Nemeth G, Palumbo A and Naftolin F (1995) The ovarian renin-angiotensin system. A paracrine-intracrine regulator of ovarian function Advances in Experimental Medical Biology 377379 389

Reynolds L, Grazul-Bilska A and Redmer D (2000) Angiogenesis in the corpus luteum Endocrine 12 1-9

Tedeschi C, Lohman C, Hazum E, Ittoop O, Ben-Shlomo I, Resnick CE, Payne DW and Adashi EY (1994) Rat ovarian granulosa cell as a site of endothelin reception and action: attenuation of gonadotropinstimulated steroidogenesis via perturbation of the A-kinase signaling pathway Biology of Reproduction 51 1058-1065

Varga B, Horvath E, Folly G and Stark E (1985) Study of the luteinizing hormone-induced increase of ovarian blood flow during the estrous cycle in the rat Biology of Reproduction 32 480-488

Wiltbank MC, Dysko RC, Gallagher KP and Keyes PL (1988) Relationship between blood flow and steroidogenesis in the rabbit corpus luteum Journal of Reproduction and Fertility 84 513-520

Yoshimura Y (1997) The ovarian renin-angiotensin system in reproductive physiology Frontier of Neuroendocrinology 18 247-291

Received 7 October 2002.

First decision 18 November 2002.

Revised manuscript received 30 January 2003.

Accepted 11 February 2003. 